\title{
“STAKEHOLDERS” COMO ATORES À CONCEPÇÃO ECOLÓGICA NO DIREITO
}

\author{
Tainá Fernanda Pedrini ${ }^{1}$ \\ Marcelo Buzaglo Dantas ${ }^{2}$ \\ Recebido em 16/12/2020 \\ Aceito em 21/12/2020
}

\begin{abstract}
RESUMO
Objetiva-se analisar a participação dos "stakeholders", mediante a visão sistêmica, à construção do pensamento ecológico no Direito. Para tanto, inicialmente, faz-se o embasamento histórico das ideias sistêmicas, no que tange ao lapso temporal em que houve superação de visões holísticas às mecanicistas, bem como, ao final, a nova roupagem atribuída, denominada sistêmica. Em seguida, aprofunda-se o estudo sobre as teorias sistêmicas, principalmente, em Luhmann, que destoaram de ideais mecanicistas. Por fim, identificam-se os "stakeholders", no caso, a sociedade, e a possibilidade de contribuição à "autopoiesis" ecológica do Direito.
\end{abstract}

Palavras-chave: "Stakeholders"; Natureza; Direito Sistêmico.

\section{STAKEHOLDERS AS ACTORS IN ECOLOGICAL CONCEPTION IN LAW}

\begin{abstract}
The purpose is to analyze the participation of stakeholders, through the systemic view, to the construction of ecological thinking in Law. Therefore, initially, the historical basis of systemic ideas is made, with regard to the time lapse in which there was an overcoming of holistic visions to mechanists, as well as, in the end, the new vestment attributed, called systemic. Then, the study of systemic theories is deepened, mainly in Luhmann, which clashed with mechanistic ideals. Finally, we identify the stakeholders, in these case, the society, and the possibility of contributing to the ecological "autopoiesis" of the Law.

Keywords: "Stakeholders". Nature. Systemic Law.
\end{abstract}

\section{INTRODUÇÃO}

Ao longo do tempo, concomitantemente, sociólogos, filósofos e juristas debateram sobre as concepções de mundo e a relação do ser humano aos demais seres do planeta, bem como a vivência em Sociedade . O respeito inicial à Natureza, de modo contemplativo, transmudou-se à dominação

\footnotetext{
${ }^{1}$ Coordenadora do Curso de Direito Uniasselvi, campus Brusque/SC. Assessora Jurídica. Doutoranda em Ciência Jurídica pela Università degli Studi di Perugia/ITA e pela Universidade do Vale do Itajaí. Mestra em Ciência Jurídica pela Widener University, Delaware Law School e pela Universidade do Vale do Itajaí. Pós-graduada em Direito Tributário pelo Instituto Brasileiro de Estudos Tributários (IBET) e em Registral e Notarial pela Faculdade Damásio. Pós-graduanda em Direito Constitucional pela Academia Brasileira de Direito Constitucional (ABDConst). E-mail: <tainapedrini@live.com>. CV lattes: http://lattes.cnpq.br/7222274253824129.

${ }_{2}$ Mestre e Doutor em Direitos Difusos e Coletivos pela PUC-SP, com estágio de Doutoramento na Pace Law School. Pós-Doutor e Docente Permanente nos Programas de Pós-Graduação da UNIVALI.
} 
dela, com o início das revoluções científicas. Teóricos buscaram justificar os processos de transição, de modo a defender ou divergir sobre a utilização indeliberada de recursos comuns.

O processo de industrialização e o fim da Modernidade, principalmente, por seus reflexos ambientais, culminou no que Ulrich Beck denomina de Sociedade de Risco. Isso porque "começam a convergir na continuidade dos processos de modernização as situações e os conflitos sociais de uma sociedade que "distribui riquezas" com uma sociedade "que distribui riscos"” (BECK, 2010, p. 25).

Nesse contexto, a ideia de externalização dos danos causados por meio do congestionamento do uso da Natureza, vista à época como infinita, gerou novas discussões e, também, inovadora roupagem à contemplação da ordem cósmica, conhecida como holística: o pensamento sistêmico.

O presente artigo, à vista disso, objetiva analisar, sob o enfoque sistêmico, a possibilidade de participação dos "Stakeholders", como agentes de degradação, à construção de um pensamento ecológico, realizando, para tanto, corte epistemológico na construção e aplicação do Direito.

A relevância da pesquisa tem valor e fundamentos históricos. Rememora acontecimentos que deixaram consequências, muitas vezes, irreversíveis. No âmbito internacional, as Grandes Guerras Mundiais, por exemplo, representaram desastres de toda monta: redução populacional, ataques nucleares, utilização de substâncias químicas, entre outros. No Brasil, há pouco, o drama de Mariana demonstra imperiosa discussão sobre mecanismos eficientes à concretização de premissas fundamentais à proteção da Natureza, utilizando de meios alternativos aos existentes.

Ainda, no que tange à relevância da pesquisa, atenta-se ao vácuo teórico existente na produção científica quanto ao tema e recorte a que se propõe o presente relatório de pesquisa. $\mathrm{Na}$ problemática, levanta-se: a participação dos "Stakeholders" é relevante à construção do Direito, de modo a influenciá-lo e ser, concomitantemente, influenciado?

Quanto à metodologia empregada na fase de investigação, utilizou-se o Método Indutivo. Acionou-se as Técnicas do Referente, da Categoria , do Conceito Operacional e da Pesquisa Bibliográfica.

\section{A CONSTRUÇÃO HISTÓRICA DO PENSAMENTO ECOLÓGICO SISTÊMICO}

A concepção Antiga e Medieval, aproximadamente entre 700 a.C e 1.500, do universo é direcionada à contemplação da ordem cósmica . Trata-se da "visão holística do mundo como um kósmos, da Terra como um generoso presente de Deus à humanidade como um todo, e de abundância de riquezas coletivamente acessíveis a todos". (FRITJOF; MATTEI, 2018, p.81). A percepção aristotélica (384-322 a.C), por exemplo, não limitava o universo às características físicas, mas o 
vislumbrava de forma orgânica, viva e dotado de espiritualidade. Para Aristóteles, o humano não estaria contra a Natureza , mas, sim, com a Natureza.

Em contraposição, na Modernidade, aproximadamente entre 1500-1750, o crescimento populacional aliado à necessidade de subsistência da Sociedade e, para além dela, o anseio em satisfazer interesses meramente materiais desencadeou, com a evolução da Ciência , o início da utilização da Natureza como mercadoria - e, logo, a dissociação entre os seres: humano e Natureza.

Essa transição - do "cosmos" à visão do mundo como uma máquina, objeto de domínio e exploração do ser humano, veiculada pela teoria denominada "mecanicista", nos séculos XVI e XVII - obteve essencial justificação nos pensamentos da época, especialmente, de Galileu Galilei .

A mudança de ideais, conquanto, não influenciou somente as Ciências exatas, como astrologia, matemática e física. Não raro, filósofos se tornaram experientes do Direito e da Política, exercendo justificação teórica posterior ao movimento.

Nesse viés, o transcurso dos pensamentos medievais aos modernos correspondeu à superação do Direito Natural Holístico ao Antropocêntrico. Conforme Capra e Mattei (2008, pág. 104), considera-se holismo, "a concepção da realidade em que a religião, a filosofia natural, a política e o direito são entendidos como um todo contínuo, [que] caracterizava o pensamento do século XIV” e cedeu lugar ao racionalismo ou antropocentrismo.

Com a Revolução Científica, na era do Antropoceno, cujo prestígio é devido a "escritores como Nicolau Maquiavel (1469-1527), Jean Bodin (1483-1546) e Thomas Hobbes, e reforçada pela teologia de Martinho Lutero (1483-1546)" (FRITJOF; MATTEI, 2018, p. 122), tem-se a ideia de que, “em questões de soberania, a força faz o direito. Além disso, a riqueza das nações soberanas podia ser avaliada pelo tamanho do mercado que elas foram capazes de criar controlar" (FRITJOF; MATTEI, 2018, p. 122).

As consequências da adesão do Direito às ideias mecanicistas, bem como a chegada do século XX, como marco à expansão e o estreitamento das relações interestatais, que se denominou Globalização, e do período doutrinariamente estabelecido como Revolução Industrial trouxeram à tona a necessidade de coexistência harmônica, interdependente e responsável entre seres humano e ambiente.

Isso porque, ao final do período, os poderes estavam nitidamente distribuídos de forma desigual - como ainda está - e tal constatação fez com que a produção científica, principalmente, demonstrasse preocupação ao cenário.

Segundo Bourdieu (2001, p. 275), “quando os poderes estão desigualmente distribuídos, em vez de se mostrar como um universo de possíveis igualmente acessíveis a todo o sujeito possível", também considerando, aqui, a Natureza como sujeito de direitos, "o mundo econômico e social se 
apresenta como um universo balizado, semeado por injunções e proibições, por signos de apropriação e exclusão".

Pode-se dizer que as mudanças desencadeadas por meio das transições políticas, sociais e econômicas, até o século XX, foram determinantes para uma nova visão de Natureza. Isso porque, com o advento da Globalização, os impactos de problemas, anteriormente, de visão regional ou nacional, passaram a transcender as linhas geográficas imaginárias atribuídas aos países no globo. Principalmente, os problemas pertinentes "à poluição atmosférica, que ganharam contornos mais acentuados após a Segunda Grande Guerra, a exemplo da chuva ácida [...] e do efeito estufa [...] de proporções globais” (TRENNEPOHL, Terence, 2010, p. 31).

Ressalta-se, ainda, que, em épocas anteriores aos referidos marcos históricos, o problema dos recursos naturais e sua escassez não era considerado sequer como possibilidade. "Seria improvável, por exemplo, conceber a idéia (sic) de escassez no período da idade média ou até mesmo durante os primeiros passos da revolução industrial" (AYDOS, Elena de Lemos Pinto, 2010 p. 50). À época, havia a concepção de que "as intervenções do homem no meio ambiente eram ainda superficiais e insignificantes em face à magnitude e permanência da natureza" AYDOS, Elena de Lemos Pinto, 2010, 50).

A percepção da relação imbricada entre a Sociedade e a Natureza, devido à consciência adquirida nesse lapso temporal, foi, portanto, consequência do descobrimento da Sociedade de Riscos. Nela, as autoameaças são "sistematicamente produzidas e aceitas pelo homem, já que estão conforme aos padrões da sociedade industrial. Soma-se à crença na sustentabilidade de tal modelo" (SARAIVA, Pery Neto, 2010, p. 19) porque, realmente, "nenhum acontecimento, até então, levava a pensar o contrário" (SARAIVA, Pery Neto, 2010, p. 19).

A Natureza, observada somente sob o aspecto dos recursos comuns gerados e, não, como ser integrante e essencial à subsistência da Teia da Vida, traz incentivo racional à sua utilização em máxima potencialidade e rememora as pesquisas de Garret Hardin (1968), especialmente, com relação à "Tragédia dos Comuns". Como um sistema de seres distribuídos no universo, a utilização máxima da Natureza traz potencial exaustão dos recursos a ela inerentes ou, ao menos, seu certo congestionamento, como já observado na atualidade. Consequentemente, àqueles que possuem acesso livre a ela, internalizam os benefícios de seu uso e, de forma desproporcional, externalizam os aspectos negativos à Sociedade.

Isso porque, o risco, apesar de atingir a Sociedade como um todo, é "distribuído desigualmente, assim como a possibilidade de destruição por ele causada. As camadas mais pobres da sociedade geralmente são as mais afetadas, em razão da localização de sua moradia, dificuldades de contornar essas situações de risco" (PEDRINI, Tainá Fernanda, 2018), bem como a insuficiência de 
amparo estatal posterior à ocorrência.

Esse contexto atual, somando à "concepção romântica da natureza "como uma grande totalidade harmônica" [...]" trouxe nova roupagem ao pensamento holístico e, como evolução dele, advieram as ideias sistêmicas. "As ideias da Terra viva, formuladas por Leonardo da Vinci no século XV e pelos cientistas românticos no XVII, contêm alguns elementos chaves de nossa teoria contemporânea de Gaia" . "A teoria de Gaia olha para a vida de maneira sistêmica, reunindo geologia, microbiologia, química atmosférica e outras disciplinas cujos profissionais não estão acostumados a se comunicarem uns com os outros" (CAPRA, 2018, p. 83).

Segundo Machado e Aquino (2020, p.59), deve-se disseminar o bem viver. "É necessário nos depreender dessa visão utilitarista do mundo natural, como se existisse para meramente suprir nossas necessidades. Somos parte da Natureza e todos vivem em relação de interdependência com as demais formas a vida". Nesse sentido, a coletividade "é responsável pelo equilíbrio da vida na Terra".

No plano do Direito, a constatação da interdependência dos seres remete à nova roupagem sobre o conceito de comunidade, ao tratamento dado às relações de todas as naturezas, bem como aos seres como integrantes de um único sistema. No que tange ao corte epistemológico da pesquisa, essa contextualização obteve como fundamento a evolução das Teorias Sistêmicas, à presente pesquisa, especificamente, a noção de "autopoiesis" do Direito e interdisciplinaridade.

Independente da forma de positivação atual, isto é, da maneira de inclusão nas leis internas, o Meio Ambiente é um autêntico Direito Humano, tanto pela relação direta e até condicional do direito à vida como, também, pela grande quantidade de outros Direitos Humanos que com ele estão diretamente relacionados. Hoje, expressiva quantidade de Tratados e Convenções Internacionais apresentam como objeto a proteção e a defesa do Meio Ambiente e não deixam margem para qualquer dúvida sobre a caracterização dele como autêntico Direito Humano (PEDRINI; BODNAR, 2017, p. 75-76).

\section{SUSTENTABILIDADE: UMA COMPREENSÃO ECOSÓFICA}

Um dos maiores desafios do século XXI, após 40 anos de tentativas para tornar eficaz as questões da Sustentabilidade, continua sendo a compreensão sobre a importância desse imperativo que faz do nosso século a diferença acentuada em torno das diferentes atividades humanas. Essa compreensão acerca da Sustentabilidade requer uma sensibilidade mais acentuada em torno não apenas das questões ambientais, mas daquilo que minimamente se convencionou chamar triple bottom line da Sustentabilidade, ou seja, o ambiental social e o econômico.

No entanto, e para fins desta pesquisa, se torna interessante enfatizar a importância da 
Sustentabilidade como vetor de mudança na atividade empreendedora para que a produção do capital não faça com que as pessoas deixem de ser mais seres humanos e vivam perspectivas únicas de sobrevivência. Na verdade, a Sustentabilidade social e a Sustentabilidade ambiental, por exemplo, formam novos padrões de se pensar o desenvolvimento civilizacional a partir das características próprias dos seres e os seus ambientes.

Por esse motivo, a teoria sistêmica fornece elementos necessários para se identificar quais são os elementos comuns que favorecem essa interconexão entre campos de saberes diferentes. Qualquer leitura inicial sobre o tema da Sustentabilidade evidencia a necessidade de uma racionalidade que não pode ser pensado exclusiva e isoladamente sob o ângulo da esfera ambiental, social ou econômica.

Pensar a Sustentabilidade significa encontrar elementos de comunicação que permitam o trânsito entre diferentes estruturas de conhecimento e experiência sensível. Essa não é a tarefa mais simples que se pode exigir da interação entre sustentabilidade ambiental e social. Na verdade, esse pressuposto é o mais elementar que impulsiona todas as outras análises as quais devem ser realizadas sob as perspectivas dessa nova exigência racional. Talvez, a palavra emergência traga luzes ao esclarecimento desse fenômeno e sirva de fomento para uma Ecosofia do Sensível .

A ideia de emergência parece concordar com fundamento teórico do direito sistêmico. Ao se pensar sobre a questão daquilo que emerge, que se torna visível aos olhos humanos, percebe-se a conexão entre diferentes a formas de pensar, de agir, de conviver. A emergência de um direito sistêmico e fundado numa compreensão ecosófica o considera como pertinente cada uma das ligações que são realizadas, ou seja, na precisa e enxuta fórmula de Phil Anderson: "Mais é diferente". É nesse contexto que o mundo da vida deve ser entendido como o "espírito do tempo".

Nesse caso, a "novidade do novo" (ZIZEK, 2011, p. 145) não se contrapõe a uma visão estritamente econômica, especialmente sob o ângulo da Sustentabilidade ambiental ou social, como é o caso da Modernização Ecológica . Essa expressão denota a busca pelo Desenvolvimento Sustentável cujo paradigma é a busca do aperfeiçoamento lógico a partir da exploração da natureza e os diferentes ambientes que a compõem.

Qualquer leitura mais rigorosa sobre o tema da Sustentabilidade sabe que a sua matriz é ecologia e o desenvolvimento das vidas não pode estar sob o jugo e a submissão de ambientes de seres ao os juízos de necessidades dos seres humanos. Por esse motivo, cada conexão estabelecida por um direito sistêmica em diferentes subsistemas de conhecimento, de experiência sensível no cotidiano, de descoberta do em outros seres em ambientes favorece o esclarecimento necessário sobre a importância da sustentabilidade, em sua matriz ecológico, ser entendida como paradigma civilizar acional do século XXI. 
A partir desse cenário, o estudo do direito constitucional já apresenta essas hipóteses devidamente registradas na Constituição do Equador e da Constituição boliviana. Na primeira temos um marco que rompe o antropocentrismo na interpretação dos sujeitos de direito. Na segunda, identifica-se, pela leitura do artigo $8^{\circ}$, o princípio da harmonia . Todos esses elementos sugerem que as respostas do direito não possam ser centradas num reducionismo lógico, como aquele previsto por Kelsen, pois os fenômenos mundiais são interdependentes e complexos.

Entender os fenômenos sociais, ambientais e econômicos sobre suas características é o primeiro passo para que se possa compreender, de modo sistêmica, o direito do século XXI. A sustentabilidade, em suas de fé, Oportunismo e demandas postas que sejam apropriadas conforme a lógica dessa complexidade em seus diferentes graus de comunicação. Dentre os possíveis cenários que se pode citar por meio da compreensão ecosófica da Sustentabilidade, os stakeholders são manifestação de uma comunicação, uma linguagem e racionalidade própria dessas características de uma Sustentabilidade em sua tríplice acepção.

\section{O PAPEL DOS “STAKEHOLDERS” À ECOLOGIA NO DIREITO ${ }^{3}$}

Anteriormente, observou-se que a dependência inexorável do ser humano à Natureza demonstrou, com as experiências históricas, a "razão pela qual grande parte dos maiores desafios da sociedade na atualidade, de uma ou de outra maneira, está relacionada com problemas ecológicos" (MONTERO, 2014. p. 3).

A humanidade, nesta pesquisa dissociada da Natureza, meramente, para fins de melhor compreensão, é dela, na verdade, parte integrante e não pode ser "mera expectadora de degradação do meio ambiente. A responsabilidade deve assegurar e proteger os indivíduos sob a ameaça de extinção, em razão de um colapso ambiental que ocorre gradativamente em desfavor da Natureza" (ARIZIO, 2017. p. 21).

Buscar alternativas, portanto, que incentivem e mitiguem práticas humanas que destoem de objetivos sustentáveis e prejudiquem o presente e o futuro da coletividade é imprescindível. O Direito, nesse contexto, como objeto de construção cultural e, no seu sentido normativo, deve, também, compreender o caráter sistêmico dessa dinâmica, pois a Sustentabilidade, no seu significado jurídico , tem como premissa de ação esse entendimento.

Os "Stakeholders" podem ser grandes alvos ou meios à concretização desses objetivos. Conceituados como "público de interesses ou públicos estratégicos" (ROCHA, 2010, p. 1), podem ser divididos por finalidades específicas, em grupos sociais. É o consenso dos seres humanos, do meio em

\footnotetext{
${ }^{3}$ Título produzido a partir de PEDRINI, 2020.
} 
se inserem, que se extraem modelos de organização (LUHMANN, 2007). Por intermédio ele, ao mesmo tempo, o Direito é influenciado e exerce controle.

Segundo Sérgio Ricardo Fernandes de Aquino (2017, p. 181), a Sustentabilidade não corrobora com um Direito que desconhece "o intenso fluxo desse rio heraclitano chamado mundo. [...] O Direito, e suas fontes, não se restringe apenas às atividades estatais legislativas ou judiciárias, mas modifica-se na medida em que se ampliam os atores sociais por meio dos fluxos globalizatórios, ou seja, transita-se de um sistema duallevel para outro [...] multilevel”.

A Sociedade, nessa percepção, "tem clamado por uma mudança de comportamento na vida cotidiana, por meio da Educação e de campanhas voltadas à preservação do meio ambiente" (ARIZIO, 2017, p. 25). O mercado, como grupo interessado, tem avançado nos projetos atinentes à Sustentabilidade, porquanto, ao constatar essa modificação "busca atrair consumidores oferecendo produtos e serviços sustentáveis. Essa nova postura indica que o domínio do ser humano sobre a Natureza, em condição predatória e exploração sem limite, deve ser superada, como condição de Justiça” (ARIZIO, 2017, p. 25).

Conforme Rocha e Goldschmidt (2020, p. 1), o relatório anual das Empresas, anteriormente, "também denominado Annual Report, tinha como foco mostrar aos acionistas os principais resultados financeiros obtidos pela Empresa no período de um ano". Com a mudança de comportamento em relação ao Mercado, hoje, esses relatórios alargaram seu público alvo e, nas "multinacionais e empresas de médio e grande porte[,] são chamados: "Relatório de Sustentabilidade" e, cada vez mais[,] seguem a metodologia internacional da Global Report Initiative (GRI)”.

Segundo eles (ROCHA; GOLDSCHMIDT, 2020, p.1), os "indicadores GRI foram criados por uma instituição internacional independente cuja missão é desenvolver um padrão internacional de relatórios de sustentabilidade". Integra-a um "grupo que representa stakeholders de diversas nacionalidades [...] e possui quatro princípios básicos: a materialidade, o engajamento com stakeholders, o contexto de sustentabilidade e a abrangência".

Isso ocorreu porque, hodiernamente, somente a lucratividade não é mais "suficiente para assegurar o inteiro teor das expectativas que o proprietário tem com relação aos seus investimentos, ou seja, de utilizar a empresa como instrumento viabilizador da elevação do valor de sua riqueza" (SOUSA; ALMEIDA, 2006, p.2).

Para Sousa e Almeida (2006, p.2), portanto, gerar lucro, como um fato econômico posterior, não evidencia a "capacidade ou precondição para que a empresa prossiga gerando resultados positivos no futuro". Nesse sentido, um conjunto de fatores é necessário ao sucesso empresarial, pois ela, a Empresa, deve se apresentar "para o mercado, com o potencial necessário para continuar prosperando". 
Para tanto, a ênfase no valor da Empresa ganhou destaque entre as preocupações principais da alta gestão, nos últimos anos, em detrimento à busca do lucro como um fim em si. "A ênfase na criação de valor, além de atender diretamente aos interesses dos investidores, é mais do que uma operação aritmética de Receitas menos Despesas ou de Lucro/Investimento" (SOUSA; ALMEIDA, 2017, p. 4). A adoção de um modelo estreito de criação de valor econômico, em que questões sociais são tratadas fora do escopo dos negócios, está ultrapassada.

Criar valor envolve, ao menos, quatro aspectos: perspectiva de longo prazo; expectativa de realização de ganhos pelos investidores; dimensão de risco e retorno; e responsabilidade social. A última abrange os consumidores, recursos naturais, recursos humanos e mantenedores - isto é, aqueles que dependem do sucesso da Empresa, como fornecedores, instituições financeiras, proprietários e funcionários (SOUSA; ALMEIDA, 2017, p .4).

Nesse contexto, "um dos grandes méritos da teoria luhmanniana está em superar a mera observação de atores e avançar para o estudo das comunicações que são travadas entre os atores sociais. Ocasião em que o direito passa a figurar como um meio capaz de viabilizar a estabilização das relações" (PORTUGAL, 2013, p. 7).

\section{CONSIDERAÇÕES FINAIS}

Os argumentos apresentados em evidência de que forma direito positivo se tornou insuficiente para trazer respostas que sejam próprias de cada fenômeno conforme suas características, bem como pela complexidade do século XXI. A compreensão e causou fica da sustentabilidade e Movimento dos stakeholders sintetizam a preocupação do direito sistêmico em esclarecer de que forma o direito se torna capaz de cumprir com seus objetivos de organização social aliando-se os interesses regionais e globais.

Constata-se que essa não é a tarefa mais simples, mas é a demanda de nosso século como forma de integração entre homem e natureza como comunidade viva que precisa ser respeitada e protegida. Por esse motivo a sustentabilidade insistir numa Ecosofia do Sensível, ou seja, a interação entre a dimensão dental econômica e social sinaliza, numa lógica sistêmica, quais são os elementos comuns entre campos de saberes diferentes que permite buscar e efetivar meios de proteção e conservação, de adaptação e prosperidade para que haja o desenvolvimento humano. Essa condição, no entanto, somente ocorre desde que se saiba respeitar os limites físicos, químicos e biológicos dos diferentes seres $\mathrm{e}(\mathrm{m})$ seus ambientes.

Essa é a lógica que o direito sistêmico opera a fim de permitir que hajam atitudes em prol do reconhecimento da Natureza como "ser próprio" e de como cada pessoa é um dos membros 
integrantes dessa comunidade viva. Por esse motivo, a hipótese de pesquisa provisoriamente descrita na Introdução deste texto restou confirmada pelo fundamento teórico apresentado porque a participação dos "Stakeholders", na dimensão do direito sistêmico, se torna um comportamento de via dupla, de se influenciar e ser influenciado, já que as múltiplas opções - na expressão de Phil Anderson: "Mais é diferente" - sinalizam a necessidade de uma atitude em prol da Sustentabilidade a partir desse variedade de possibilidades para se ter prosperidade, adaptação e manutenção de nosso mundo.

\section{REFERENCIAS DAS FONTES CITADAS}

ADLER, Mortimer J. Aristóteles para todos: uma introdução simples a um pensamento complexo. Tradução de Pedro Sette-Câmara. São Paulo: É Realizações, 2010. Título Original: Aristotle for Everybody: difficult thought made easy.

ALMEIDA, Fernando. Experiências empresariais em sustentabilidade: avanços, dificuldades e motivações de gestores e empresas. Rio de Janeiro: Elsevier, 2009.

AQUINO, Sérgio Ricardo Fernandes de. (Contra o) eclipse da esperança: escritos sobre a(s) assimetria(s) entre Direito e Sustentabilidade. Itajaí: Univali, 2017.

AQUINO, Sérgio Ricardo Fernandes de; MACHADO, Maykon Fagundes. Estudos sobre o direito à sustentabilidade como direito à existência. Florianópolis: Habitus, 2021.

ARIZIO, Silvia Helena. Manifesto para uma justiça ecológica: sua importância acerca do direito das águas. Erechim: Deviant, 2017.

AYDOS, Elena de Lemos Pinto. Tributação ambiental no Brasil: fundamentos e perspectivas. 2010. Dissertação (Mestrado em Direito). Universidade Federal de Santa Catarina, Florianópolis, SC.

BAUMAN, Zygmunt. Globalização: as consequências humanas. Tradução de Alexandre Werneck. Rio de Janeiro: Jorge Zahar, 1999, p. 06. Título Original: Globalization: the human consequences.

BECK, Ulrich. Sociedade de risco: rumo a uma outra modernidade. Tradução de Sebastião Nascimento. São Paulo: Editora 34, 2010. Título Original: Risk societty: towards a new modernity.

BOFF, Leonardo. Sustentabilidade: o que é - o que não é. 4 ed. Rio de Janeiro: Vozes, 2015.

BUCKINGHAM, Will et al. O livro da filosofia. Tradução de Douglas Kim. 2 ed. São Paulo: Globo Livros, 2016.

BOURDIEU, Pierre. Meditações Pascalianas. Tradução de Sergio Miceli. Rio de Janeiro: Bertrand Brasil, 2001. Título Original: Méditations pascaliennes.

BRASIL. Lei n. 6.938, de 31 de agosto de 1981. Política Nacional do Meio Ambiente.

Brasília, Disponível em: <http://www.planalto.gov.br/ccivil_03/leis/L6938.htm>. 
FERNANDES, Edison Carlos. Paz tributária entre as nações: Teoria da aproximação tributária na formação dos blocos econômicos. 2005. $183 \mathrm{f}$. Tese (Doutorado) - Curso de Direito, Pontifícia Universidade Católica de São Paulo, São Paulo, 2005.

FERRY, Luc. Aprender a viver: sabedoria para os novos tempos. Tradução de Véra Lucia dos Reis. Rio de Janeiro: Objetiva, 2012. Título Original: Apprendre à vivre: Traité de philosophie à l'usage des jeunes générations.

FRITJOF, Capra; MATTEI, Ugo. A revolução ecojurídica: o direito sistêmico em sintonia com a natureza e a comunidade. Tradução de Jeferson Luiz Camargo. São Paulo: Cultrix. 2018. Título Original: The ecology of law.

FRITJOF, Capra; MATTEI, Ugo. A teia da vda: uma nova compreensão científica dos sistemas vivos. Tradução de Newton Roberval Eichemberg. São Paulo: Cultrix, 2006.

HARDIN, Garret. The tragedy of the commons. Science. Vol. 162. Dez. 1968.

LUHMANN, Niklas. La sociedad de la sociedad. México: Herder, 2007.

MONTERO, Carlos Eduardo. Tributação ambiental: reflexões sobre a introdução da variável ambiental no sistema brasileiro. São Paulo: Saraiva, 2014.

PASOLD, Cesar Luiz. Metodologia da pesquisa jurídica: teoria e prática. 11 ed. Florianópolis: Conceito Editorial; Millennium Editora, 2008.

PORTUGAL, Daniela. A autopoiese no Direito e o funcionalismo sistêmico de Günther Jakobs na aplicação da Lei Penal. Cadernos do Programa de Pós-Graduação em Direito, Universidade Federal do Rio Grande do Sul. vol. VIII. n. 2. Ano 2013. p. 7. Disponível em: < https://seer.ufrgs.br/ppgdir/article/view/43130/28204>.

PEDRINI, Tainá Fernanda. Drama de Mariana: memórias entre a lama. Disponível em: $<$ http://conversandocomoprofessor.com.br/2018/01/29/drama-de-mariana-memorias-entre-alama/>.

PEDRINI, Tainá Fernanda. Homicídio de crianças indígenas: colonialidades e direitos fundamentais. Rio de Janeiro: Lumen Juris, 2017.

PEDRINI, Tainá Fernanda. BODNAR, Zenildo. Efetivação dos Direitos dos Animais e o Registro de Títulos e Documentos. In MOREIRA, Ana Selma (Org.). Eu sou animal: uma revolução social em busca do antiespecismo. Joinvile: Manuscritos Editora, 2019.

RIBEIRO, Job Antonio Garcia; CAVASSAN, Osmar. Os conceitos de ambiente, meio ambiente e natureza no contexto da temática ambiental: definindo significados. GÓNDOLA Enseñanza y Aprendizaje de las Ciencias. vol. 8, n.2, julio-diciembre del 2013.

ROCHA, Thelma; GOLDSCHMIDT, Andrea (Coords). Gestão dos Stakeholders: como gerenciar o relacionamento e a comunicação entre a empresas e seus públicos de interesse. São Paulo: Saraiva, 2010.

SARAIVA, Pery Neto. A prova na jurisdição ambiental. Porto Alegre: Livraria do 
Advogado, 2010.

SOUSA, Almir Ferreira de; ALMEIDA, Ricardo José de. O valor da empresa e a influência dos stakeholders. São Paulo: Saraiva, 2006.

SOUZA, Maria Cláudia da Silva Antunes de; MAFRA, Juliete Ruana. Avaliação ambiental estratégica: agindo em favor do desenvolvimento sustentável. In SOUZA, Maria Cláudia da Silva Antunes de. Avaliação ambiental estratégica: reflexos na gestão ambiental portuária Brasil e Espanha. Belo Horizonte: Editora Vorto, 2017.

TRENNEPOHL, Terence. Direito ambiental. 5.ed. São Paulo: Saraiva, 2010.

ZANON JUNIOR, Orlando Luiz. Curso de Filosofia Jurídica. Florianópolis: Empório do Direito, 2016. 